University of New Hampshire

University of New Hampshire Scholars' Repository

Physics Scholarship

Physics

$7-8-2000$

Kinetic energy release in electron-induced decay reactions of molecular ions: $\mathrm{C} 3 \mathrm{H} 8+$ and $\mathrm{C} 3 \mathrm{H} 7+$

S. Matt

Olof E. Echt

University of New Hampshire, Olof.Echt@unh.edu

A. Stamatovic

T. D. Mark

Follow this and additional works at: https://scholars.unh.edu/physics_facpub

Part of the Physics Commons

Recommended Citation

The following article appeared in J. Chem. Phys. 113, 616 (2000); doi: 10.1063/1.481837 and may be found at http://dx.doi.org/10.1063/1.481837.

This Article is brought to you for free and open access by the Physics at University of New Hampshire Scholars' Repository. It has been accepted for inclusion in Physics Scholarship by an authorized administrator of University of New Hampshire Scholars' Repository. For more information, please contact Scholarly.Communication@unh.edu. 


\section{AIP Chemicital Physics}

Kinetic energy release in electron-induced decay reactions of molecular ions: $\mathrm{C} 3 \mathrm{H} 8+$ and $\mathrm{C} 3 \mathrm{H} 7+$

S. Matt, O. Echt, A. Stamatovic, and T. D. Märk

Citation: J. Chem. Phys. 113, 616 (2000); doi: 10.1063/1.481837

View online: http://dx.doi.org/10.1063/1.481837

View Table of Contents: http://jcp.aip.org/resource/1/JCPSA6/v113/i2

Published by the American Institute of Physics.

\section{Additional information on J. Chem. Phys.}

Journal Homepage: http://jcp.aip.org/

Journal Information: http://jcp.aip.org/about/about_the_journal

Top downloads: http://jcp.aip.org/features/most_downloaded

Information for Authors: http://jcp.aip.org/authors

\section{ADVERTISEMENT}
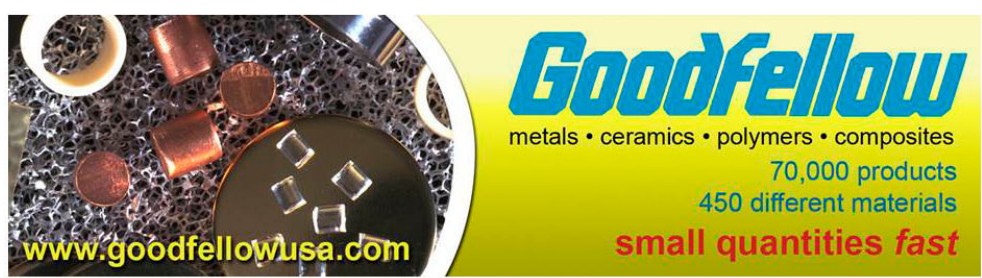


\title{
Kinetic energy release in electron-induced decay reactions of molecular ions: $\mathrm{C}_{3} \mathrm{H}_{8}^{+}$and $\mathrm{C}_{3} \mathrm{H}_{7}^{+}$
}

\author{
S. Matt, O. Echt, ${ }^{\text {a) }}$ and A. Stamatovic ${ }^{\text {b) }}$ \\ Institut für Ionenphysik, Leopold Franzens Universität, Technikerstr. 25, A-6020 Innsbruck, Austria \\ T. D. Märk ${ }^{\mathrm{c})}$ \\ Institut für Ionenphysik, Leopold Franzens Universität, Technikerstr. 25, A-6020 Innsbruck, Austria, and \\ Katedra fyziky plazmy, Univerzita, Mlynska dolina F2, SK-84215 Bratislava, Slovak Republic
}

(Received 16 February 2000; accepted 10 April 2000)

\begin{abstract}
We have measured the kinetic energy release (KER) distributions for electron-induced dissociation of mass-selected molecular parent and fragment ions of propane. They are compared with distributions determined for spontaneous (metastable) dissociation. The average KER for induced dissociation of $\mathrm{C}_{3} \mathrm{H}_{8}^{+}$into $\mathrm{C}_{3} \mathrm{H}_{7}^{+}$is $13.2 \pm 1.2 \mathrm{meV}$, about $42 \%$ larger than for the spontaneous reaction. This large difference is attributed to the dramatically reduced time at which the induced reaction can be sampled. In contrast, the KER for dissociation of $\mathrm{C}_{3} \mathrm{H}_{7}^{+}$into $\mathrm{C}_{3} \mathrm{H}_{5}^{+}$, which is characterized by a large reverse activation energy, is hardly affected by the experimental time scale.

(C) 2000 American Institute of Physics. [S0021-9606(00)00826-6]
\end{abstract}

\section{INTRODUCTION}

The research literature abounds with studies of dissociative reactions of mass-selected ions which are induced by photon absorption, gas-phase collisions, or surface collisions. In some of these, the kinetic energy release (KER) was determined as well. ${ }^{1,2}$ In contrast, reports on electron-induced dissociative reactions of molecular ions are scarce. Most of them involved diatomic or other small ions with the goal of measuring absolute cross sections for fragmentation. ${ }^{3}$ Cross sections for ionization and dissociation of fullerene ions were reported by Salzborn and co-workers. ${ }^{4}$ Freiser and coworkers explored dissociative electron capture by polyatomic ions to obtain structural information from the fragment pattern. ${ }^{5}$ McLafferty and co-workers extended the technique to large multiply charged ions. ${ }^{6}$ However, except for recent work in our laboratory, ${ }^{7,8}$ the KER released in electron-induced reactions of polyatomic ions has not been measured.

Induced reactions offer the possibility of analyzing the KER for ions with very short lifetimes. There is considerable interest in the time dependence of the KER. ${ }^{9-11}$ Statistical reactions without a reverse activation energy feature a KER which increases with decreasing ion lifetime because, at the same time, the statistically distributed excitation energy in the parent ion increases. Reactions with a large reverse barrier, however, are characterized by an essentially constant, or even decreasing, KER. ${ }^{12}$ Hence, the time dependence of the KER provides information about the nature of the reaction pathway. For example, the presence of a strong time depen-

\footnotetext{
a) Permanent address: Department of Physics, University of New Hampshire, Durham, New Hampshire 03824.

b) Permanent address: Faculty of Physics, P.O. Box 638, Yu-11001 Beograd, Yugoslavia.

c) Author to whom correspondence should be addressed; electronic mail: tilmann.maerk@uibk.ac.at
}

dence in the KER of $\mathrm{C}_{60}^{+}$dissociating into $\mathrm{C}_{58}^{+}$signals the absence of a significant reverse activation energy. ${ }^{8,13}$

In past work, the time at which dissociation was measured (relative to the time of ion formation in the ion source) was varied by varying the acceleration voltages. ${ }^{11,14}$ The advent of ion traps has made it possible to greatly increase the ion lifetimes being sampled, ${ }^{13}$ but a lower limit of the order of 1 to $10 \mu$ s still exists because of the requirement to accelerate and mass select the parent ions.

In this contribution we compare the KER of spontaneous reactions, occurring on the time scale of about 11 to $14 \mu \mathrm{s}$, with that for induced reactions occurring within less than $0.75 \mu$ s after electron-impact excitation. This is accomplished by positioning a high-performance electron gun near the intermediate slit of a double focusing magnetic mass spectrometer of reverse geometry. We observe a large fractional increase of the average KER for decay of $\mathrm{C}_{3} \mathrm{H}_{8}^{+}$into $\mathrm{C}_{3} \mathrm{H}_{7}^{+}$, but a much smaller effect for decay of $\mathrm{C}_{3} \mathrm{H}_{7}^{+}$into $\mathrm{C}_{3} \mathrm{H}_{5}^{+}$. The differences are attributed to the existence of a large reverse activation energy for decay of $\mathrm{C}_{3} \mathrm{H}_{7}^{+}$into $\mathrm{C}_{3} \mathrm{H}_{5}^{+}$.

\section{EXPERIMENT}

Details of the experimental setup and data analysis have been published elsewhere. ${ }^{15}$ As shown in Fig. 1, the apparatus consists of a high-resolution, double focusing mass spectrometer (Varian MAT CH5-DF) of reversed Nier-Johnsontype geometry. Propane molecules are introduced via a capillary leak gas inlet system into the ion source where they are ionized by an electron beam of variable energy and current. Ensuing cations are extracted by a weak electric field and accelerated through a potential drop of $U_{\mathrm{ac}}=3 \mathrm{kV}$ into the spectrometer. They pass through the first field-free region (1ff for short), are then momentum-analyzed by a magnetic sector field, enter a second field-free region (2ff, length 33.3 


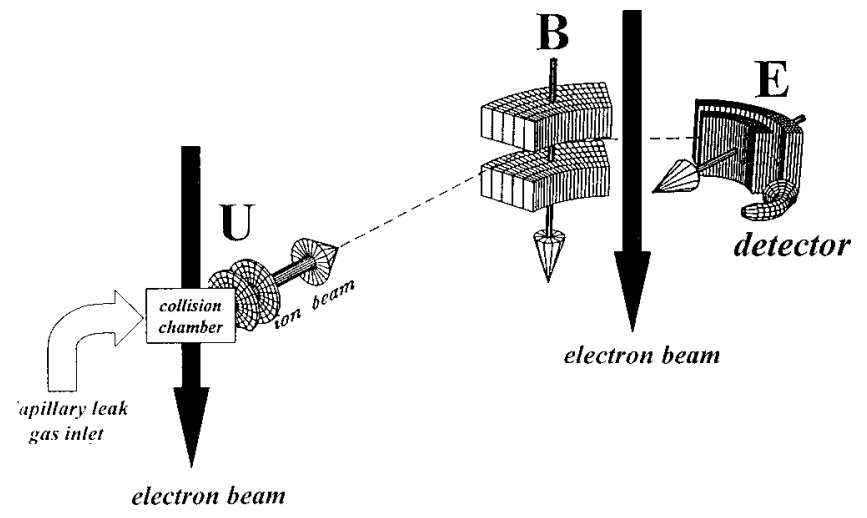

FIG. 1. Schematic view of the two-sector field mass spectrometer. Either spontaneous or electron-induced decay reactions are studied in the second field-free region.

$\mathrm{cm}$ ), pass through a $90^{\circ}$ electric sector field, and are finally detected by a channeltron-type electron multiplier operated in the single-ion counting mode.

In order to analyze the decay of mass-selected molecular ions, we select the parent ions with the magnetic sector field and analyze decay reactions in the $2 \mathrm{ff}$ by varying the voltage of the electric sector field [mass-analyzed ion kinetic energy (MIKE) scan technique $\left.{ }^{10}\right]$. The decay may be either spontaneous (metastable), or it may be induced by electrons from a high-performance, home-built electron gun. ${ }^{16}$ The electron gun is mounted just before the defining aperture between the magnetic sector and the electric sector, approximately midway between the sectors. The electron beam intersects the ion beam at $90^{\circ}$. The gun is an order of magnitude more powerful than the electron gun which we had used previously for post-ionization of fullerene cat- and anions. ${ }^{7,17}$ In this work we chose an electron energy of $150 \mathrm{eV}$ which results in an electron beam current of $7 \mathrm{~mA}$. The setting is a compromise: The electron beam current would increase further with increasing energy, but the ionization cross section of propane reaches its maximum near $75 \mathrm{eV} .{ }^{18}$

MIKE spectra are recorded as follows: The magnet is tuned to the mass of the parent ion, $m_{p}$, while the electric sector field voltage $U$ is scanned. ${ }^{10}$ Stable ions (in this work assumed to be singly charged) will have a kinetic energy of $3 \mathrm{keV}$ and pass at the nominal sector field voltage of $U_{p}$ $=509 \mathrm{~V}$. Daughter ions (mass $m_{d}$ ), formed in the $2 \mathrm{ff}$, will then pass at a voltage

$$
U_{d}=\frac{m_{d}}{m_{p}} U_{p}
$$

Equation (1) relates the position of a daughter ion peak to the position of the parent ion peak in a MIKE spectrum. In practice, the parent ion peak will have a finite width and a distinct shape which will also be imposed on the daughter ion peak. Any kinetic energy release (KER) in the reaction will further modify the peak shape of the daughter. If the MIKE peak is strictly Gaussian, then the average kinetic energy release, $\bar{\varepsilon}$, can be extracted from its full width at half maximum, $\Delta U$, with help of the relation ${ }^{19}$

$$
\bar{\varepsilon}=2.16 \frac{m_{p}^{2} U_{\mathrm{ac}}}{16 m_{d}\left(m_{p}-m_{d}\right)}\left(\frac{\Delta U}{U_{p}}\right)^{2},
$$

provided $\Delta U$ is corrected for the finite width of the parent ion peak, by subtracting the peak widths of the raw data in quadrature. The KER distribution (KERD) in the center-ofmass system is then a Maxwell-Boltzmann distribution ${ }^{19}$

$$
f(\varepsilon)=\sqrt{\varepsilon} \exp \left(-\frac{1.5 \varepsilon}{\bar{\varepsilon}}\right),
$$

where $\bar{\varepsilon}$ denotes the average KER.

If the peak in the MIKE spectrum is not a Gaussian, then the KERD has to be derived from its derivative with respect to the sector field voltage. This procedure requires smoothing of the raw spectra and deconvolution with the parent ion peak which we do by fast Fourier transform techniques. Details, including the use of ion trajectory calculations to simulate MIKE peaks for our spectrometer, have been described elsewhere. ${ }^{15}$ This procedure is unbiased, but the deconvolution procedure and the summation over the KERD may produce nonstatistical errors in $\bar{\varepsilon}$ which are difficult to quantify.

As a MIKE scan will always sample decay reactions which occur between the magnetic and electric sector, there is an important difference in the time scale between spontaneous and induced decay reactions. A parent ion (here assumed to be $\mathrm{C}_{3} \mathrm{H}_{8}^{+}$) formed in the ion source at $t=0$, will traverse the $2 \mathrm{ff}$ at a time interval $11.2 \leqslant t \leqslant 14.2 \mu \mathrm{s}$. In contrast, if the reaction is electron-induced in the $2 \mathrm{ff}$, it has to occur within $t \leqslant 0.75 \mu \mathrm{s}$ in order to contribute to the MIKE spectrum.

\section{RESULTS}

We have analyzed the following decay reactions in the second field-free region,

$$
\begin{aligned}
& \mathrm{C}_{3} \mathrm{H}_{8}^{+} \rightarrow \mathrm{C}_{3} \mathrm{H}_{7}^{+}+\mathrm{H}, \\
& \mathrm{C}_{3} \mathrm{H}_{7}^{+} \rightarrow \mathrm{C}_{3} \mathrm{H}_{5}^{+}+\mathrm{H}_{2} .
\end{aligned}
$$

In each case, the spontaneous as well as the electron-induced reactions were measured.

Figure 2(a) displays the MIKE scan for the spontaneous reaction (4). The peaks are Gaussian, except for a slightly enhanced background to the right of the daughter ion peak which is believed to stem from decay reactions in the electric sector field. ${ }^{20}$ Excellent nonlinear least-squares fits (solid lines) are obtained if we exclude the tail to the right of the daughter peak, as shown by the solid curves in Fig. 2. After correcting for the width of the parent ion peak, we derive an average KER of $\bar{\varepsilon}=9.3 \pm 1.5 \mathrm{meV}$. The error follows from the uncertainties in the widths of the Gaussians obtained by the least-squares fitting routine. The result agrees well with a value of $9.4 \mathrm{meV}$ which we had previously derived from the KERD without resorting to Gaussians. ${ }^{15}$ It also agrees well with the values reported by Medved et al. ${ }^{11}$ who fitted Gaussians to the MIKE peaks and obtained, from three independent measurements, an average of $9.6 \mathrm{meV}$ with a standard deviation of $0.3 \mathrm{meV}$.

Figure 2(b) shows the MIKE spectrum for the electroninduced reaction (4). Again, the solid lines indicate least- 


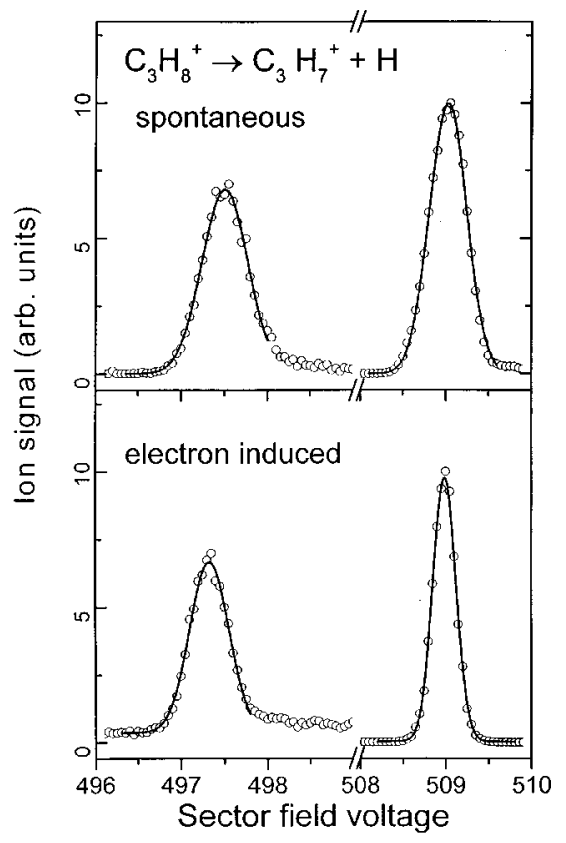

FIG. 2. Top: MIKE scan for spontaneous dissociation of $\mathrm{C}_{3} \mathrm{H}_{8}^{+}$into $\mathrm{C}_{3} \mathrm{H}_{7}^{+}+\mathrm{H}$ [reaction (4)]. The solid lines indicate least-squares fits of Gaussians. Bottom: MIKE scan for the electron-induced reaction.

squares fits over parts of the spectra. A striking result is that the parent ion peak in Fig. 2(b) is much narrower than in Fig. 2(a). Both these spectra (spontaneous and induced) were recorded with identical slit widths, although other parameters, such as the potentials in the ion extraction region, may have been different. However, we have verified that the parent ion peaks narrow whenever the electron gun in the field-free region is being operated. The effect appears to be due to the space charge produced by the intense electron beam. Details are not fully understood, but this phenomenon does not affect the KERD and the average KER because we always correct for the width of the parent ion peak recorded under identical conditions as the daughter ion peak. We derive an average KER of $\bar{\varepsilon}=13.2 \pm 1.2 \mathrm{meV}$ for the electron-induced reaction (4). Thus, electron-induced dissociation of $\mathrm{C}_{3} \mathrm{H}_{8}^{+}$ into $\mathrm{C}_{3} \mathrm{H}_{7}^{+}+\mathrm{H}$ features an average KER which is enhanced over the spontaneous reaction by $3.9 \pm 1.8 \mathrm{meV}$.

The KER distributions are readily derived from the Gaussian fits to the MIKE spectra after deconvolution with the parent ion peaks; the results are shown in Fig. 3. The shift of the distribution for the electron-induced reaction is obvious.

The MIKE spectrum and the KERD for spontaneous dissociation of $\mathrm{C}_{3} \mathrm{H}_{7}^{+}$into $\mathrm{C}_{3} \mathrm{H}_{5}^{+}+\mathrm{H}_{2}$ (reaction 5) have been published in a previous publication from our laboratory. ${ }^{15} \mathrm{In}$ Fig. 4(a) we show the corresponding MIKE spectrum for the electron-induced reaction. The daughter peak is, like in the spectrum for the spontaneous reaction, flat-topped, characteristic of a reaction which features a sizable reverse activation energy. The KERD is derived from these data as discussed in the experimental section; it is displayed in Fig. 4(b). A large threshold value in the KER is immediately apparent. The average KER for the electron-induced reaction is found from this distribution to be $397 \mathrm{meV}$, while the average KER for

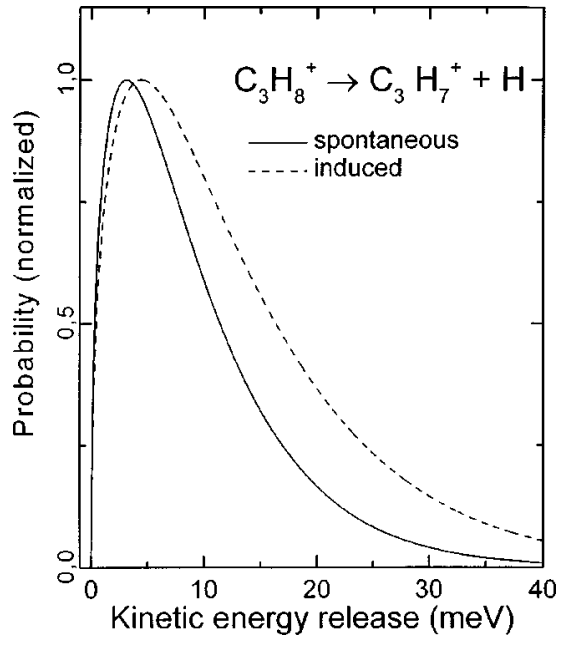

FIG. 3. KER distributions for spontaneous and electron-induced dissociation of $\mathrm{C}_{3} \mathrm{H}_{8}^{+}$into $\mathrm{C}_{3} \mathrm{H}_{7}^{+}+\mathrm{H}$, derived from the least-squares fits in Fig. 2 .

the spontaneous reaction is obtained as $386 \mathrm{meV}$. The uncertainty of these values is difficult to quantify, but is probably on the order of $10 \mathrm{meV}$. In our previous publication we had derived an average KER of $400 \mathrm{meV}$ for the spontaneous reaction, while Holmes et al. reported a value of $440 \mathrm{meV} .{ }^{19}$

\section{DISCUSSION}

In the current study we have measured the kinetic energy released in the electron-induced dissociation of massselected polyatomic ions, and compared it with the spontaneous (metastable) reaction. Table I summarizes the numeri-
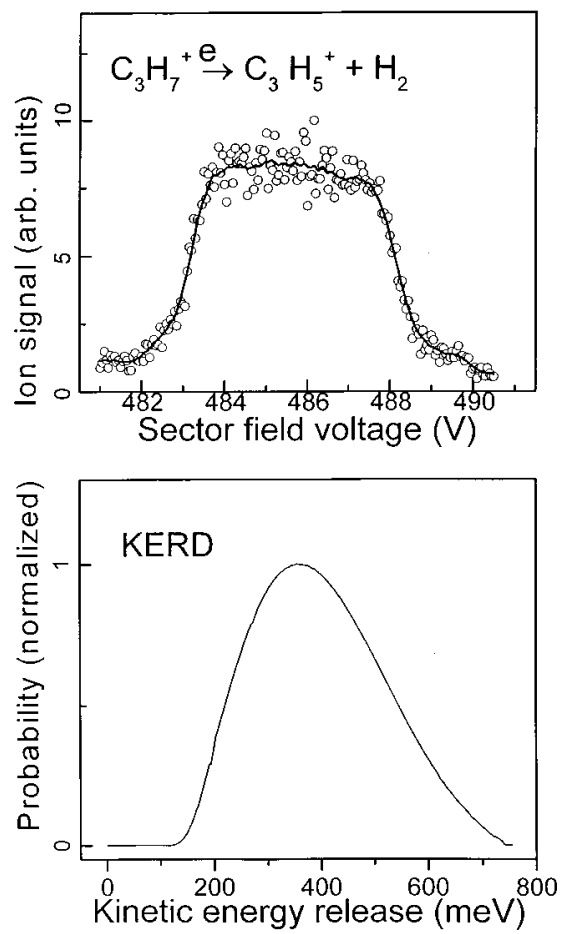

FIG. 4. Top: MIKE scan for electron-induced dissociation of $\mathrm{C}_{3} \mathrm{H}_{7}^{+}$into $\mathrm{C}_{3} \mathrm{H}_{5}^{+}+\mathrm{H}_{2}$ [reaction (5)]. The solid line results from FFT-smoothing. Bottom: The KER distribution obtained from the smooth MIKE spectrum, after deconvolution with the parent ion peak. 
TABLE I. Average kinetic energy release for spontaneous and electroninduced decay of molecular ions formed from propane by electron-impact ionization.

\begin{tabular}{ccccc}
\hline \hline Reaction & Parent & Daughter & $\bar{\varepsilon}(\mathrm{meV})$ (spont) & $\bar{\varepsilon}$ (meV) (ind) \\
\hline 4 & $\mathrm{C}_{3} \mathrm{H}_{8}^{+}$ & $\mathrm{C}_{3} \mathrm{H}_{7}^{+}$ & $9.3 \pm 1.5$ & $13.2 \pm 1.2$ \\
5 & $\mathrm{C}_{3} \mathrm{H}_{7}^{+}$ & $\mathrm{C}_{3} \mathrm{H}_{5}^{+}$ & 386 & 397 \\
\hline \hline
\end{tabular}

cal results. For reaction (4) we find a dramatic shift of the KERD (see Fig. 3), corresponding to an increase of the average KER by $42 \% \pm 26 \%$. The average KER for reaction (5), in contrast, is enhanced by a mere $3 \%$.

It should be pointed out that the average KER measured for the induced reactions only represents lower limits, because the MIKE peak is actually a superposition of the spontaneous and electron-induced signal. However, the large increase in the KER for reaction (4), but not (5), is hardly due to our inability to separate the MIKE peak into its two components.

What causes the enhancement of the average KER for the induced reaction (4), and why is the result for reaction (5) so much different? We believe that the enhancement for reaction (4) is caused by a change in the time scale over which the reaction is monitored. Furthermore, the occurrence of only a small change for reaction (5) is attributed to the existence of a large reverse activation energy.

Let us first consider the change in time scale. For reaction (4), spontaneous decay is monitored within the time interval $11.2 \leqslant t \leqslant 14.2 \mu$ s with respect to ion formation and excitation. For the electron-induced reaction, however, dissociation would have to occur within $t \leqslant 0.75 \mu \mathrm{s}$ after excitation. The effect of the time scale on the KER has been documented before. ${ }^{8,11,13}$ The effect is expected to be large if the KER reflects the (vibrational) excitation energy in the parent ion or, in other words, the nonfixed energy in the transition state. If, as in the present study, parent ions are prepared with a broad distribution of excitation energies, then contributions to the daughter ion signal measured at time $t$ will come from ions which have decay rate constants of $k \approx 1 / t$. Thus, shorter time scales imply higher rate constants, higher excitation energies, and higher average KER.

The time window over which we monitor the induced decay has no lower bound, hence we cannot apply the usual procedure to assign a most probable rate constant, $k_{m} \cdot{ }^{21}$ However, we can estimate what the effective (average) time is if the KER is observed to increase from $9.3 \mathrm{meV}$ for spontaneous decay $\left(k \approx 8 \times 10^{4} \mathrm{~s}^{-1}\right)$ to $13.2 \mathrm{meV}$. Our estimate is based on calculated values of the Rice-RamspergerKassel-Marcus (RRKM) rate constant $k(E)$ for reaction (4) where $E$ denotes the excess energy in the transition state. ${ }^{22}$ We extrapolate the published data to lower energies to include our value $k(E)$ for spontaneous decay. We assume that the average KER scales as the excess energy $E$. Hence, given the rate constant for spontaneous decay, we estimate $E_{\text {spon }}$ which we then scale by the ratio 13.2/9.3 to obtain $E_{\text {ind }}$; this is found to correspond to a rate constant of about $10^{8} \mathrm{~s}^{-1}$ or a time window of $10^{-8} \mathrm{~s}$. The result appears to be plausible.

It is also interesting to note that Lifshitz and co-workers observed a similar shift in their study of the time-dependence of the KER for dissociation of fullerene ions. ${ }^{8,13}$ A combination of pulsed photon excitation and ion trap techniques made it possible to cover a time scale of $t \approx 1$ to $90 \mu \mathrm{s}$. The observed increase in the average KER was about $60 \%$.

We now discuss reaction (5), which is lacking a significant relative increase of the average KER. The KERD (Fig. 4) immediately shows that this reaction proceeds with a large reverse activation energy, $E_{r}$. Such a situation is typical of rearrangement reactions; a large fraction of $E_{r}$ may be partitioned as kinetic energy of the products. ${ }^{2,9,10,23}$ Based on thermochemical data, Holmes et al. derive $E_{r}=240$ $\pm 60 \mathrm{meV}$ for reaction (5), $80 \%$ to $100 \%$ of which is released as translational energy of the products. ${ }^{24}$ Hence, about onehalf of the observed average KER is dominated by the contribution from the reverse activation energy. As a result, a change of the time scale and a related change of the excitation energy will have a reduced effect on the average KER. ${ }^{9}$ In addition, as argued by Lifshitz et al. ${ }^{12}$ the part of the KER that is due to the reverse activation energy may actually decrease with decreasing ion lifetime. This effect may compensate the opposite trend caused by the nonfixed energy, thus leading to a situation where the total KER does not depend on the time scale of the experiment.

In summary, we have demonstrated that electroninduced reactions of mass-selected ions, and the concomitant kinetic energy release distributions, can be measured. We have determined the KERD for two different reactions, and compared them with the corresponding KERD for the spontaneous reactions. The induced reactions appear to occur after energy randomization, hence the main difference between the spontaneous and the induced reactions is the time scale on which they are monitored.

\section{ACKNOWLEDGMENTS}

This work has been partially carried out within the Association EURATOM-ÖAW. It has been partially supported by the Österreichischer Fonds zur Förderung der Wissenschaftlichen Forschung, the Bundesministerium für Wissenschaft und Verkehr, and the Fonds zur verstärkten Förderung von wissenschaftlichen Auslandsbeziehungen, Leopold Franzens Universität, Innsbruck. We thank the referee for drawing our attention to Ref. 22.

${ }^{1}$ M. F. Jarrold, J. Illies, and M. T. Bowers, J. Chem. Phys. 79, 6086 (1983).

${ }^{2}$ N. G. Gotts and A. J. Stace, Phys. Rev. Lett. 66, 21 (1991).

${ }^{3}$ See, G. H. Dunn and N. Djuric, in Novel Aspects of Electron-Molecule Collisions, edited by K. H. Becker (World Scientific, Singapore, 1998), p. 241.

${ }^{4}$ R. Völpel, G. Hofmann, M. Steidl, M. Stenke, M. Schlapp, R. Trassl, and E. Salzborn, Phys. Rev. Lett. 71, 3439 (1993).

${ }^{5}$ R. B. Cody and B. S. Freiser, Anal. Chem. 51, 547 (1979).

${ }^{6}$ N. A. Kruger, R. A. Zubarev, D. M. Horn, and F. W. McLafferty, Int. J. Mass Spectrom. Ion Processes 185-187, 787 (1999).

${ }^{7}$ T. Rauth, O. Echt, P. Scheier, and T. D. Märk, Chem. Phys. Lett. 247, 515 (1995)

${ }^{8}$ S. Matt, R. Parajuli, A. Stamatovic, P. Scheier, T. D. Märk, J. Laskin, and C. Lifshitz, Eur. Mass Spectrom. (in press).

${ }^{9} \mathrm{~K}$. Levsen, Fundamental Aspects of Organic Mass Spectrometry (Verlag Chemie, Weinheim, 1978).

${ }^{10}$ R. G. Cooks, J. H. Beynon, R. M. Caprioli, and G. R. Lester, Metastable Ions (Elsevier, Amsterdam, 1973). 
${ }^{11}$ M. Medved, R. G. Cooks, and J. H. Beynon, Int. J. Mass Spectrom. Ion Processes 19, 179 (1976).

${ }^{12}$ C. Lifshitz, S. Gefen, and R. Arakawa, J. Phys. Chem. 88, 4242 (1984).

${ }^{13}$ J. Laskin, C. Weickhardt, and C. Lifshitz, Int. J. Mass Spectrom. Ion Processes 161, L7 (1997).

${ }^{14}$ Y. Ji, M. Foltin, C. H. Liao, and T. D. Märk, J. Chem. Phys. 96, 3624 (1992).

${ }^{15}$ S. Matt, M. Sonderegger, R. David, O. Echt, P. Scheier, J. Laskin, C. Lifshitz, and T. D. Märk, Int. J. Mass Spectrom. Ion Processes 185-187, 813 (1999).

${ }^{16}$ S. Matt, Ph.D. thesis, Universität Innsbruck, 1998.

${ }^{17}$ S. Matt, O. Echt, T. Rauth, B. Dünser, M. Lezius, A. Stamatovic, P. Scheier, and T. D. Märk, Z. Phys. D: At., Mol. Clusters 40, 389 (1997)
${ }^{18}$ V. Grill, G. Walder, D. Margreiler, T. Rauth, H. U. Poll, P. Scheier, and T. D. Märk, Z. Phys. D 25, 217 (1993).

${ }^{19}$ J. L. Holmes and A. D. Osborne, Int. J. Mass Spectrom. Ion Processes 23, 189 (1977).

${ }^{20}$ B. A. Rumpf and P. J. Derrick, Int. J. Mass Spectrom. Ion Processes 82, 239 (1988).

${ }^{21}$ C. E. Klots, J. Chem. Phys. 58, 5364 (1973).

${ }^{22}$ D. J. McAdoo, S. Olivella, and A. Sole, J. Phys. Chem. A 102, 10798 (1998).

${ }^{23}$ J. L. Holmes, A. D. Osborne, and G. M. Weese, Org. Mass Spectrom. 10, 867 (1975).

${ }^{24}$ J. L. Holmes and A. D. Osborne, Org. Mass Spectrom. 13, 133 (1978). 